\title{
RECONTEXTUALIZAÇÃO PUBLICITÁRIA DE PRÁTICAS DISCURSIVAS O CASO DO GUIA ELEITORAL
}

Ivandilson Costa é professor do departamento de Letras da Universidade do Estado do Rio Grande do Norte (UERN) e doutorando em Letras/Linguística na Universidade Federal de Pernambuco (UFPE). É membro da Associação de Linguística e Filologia da América Latina (ALFAL). E-mail: ivandilsoncosta@uern.br

\section{Resumo}

Pelo presente trabalho, buscamos investigar como um gênero pertencente a uma ordem não necessariamente mercadológica, como a do discurso político, passa a incorporar caracteres de gêneros promocionais, mais especialmente o da publicidade. A abordagem se ampara na Análise Crítica do Discurso e em outros aportes focais. Tomou-se, para tanto, um conjunto de edições do guia eleitoral relativo à campanha presidencial de 2010.

\begin{abstract}
This paper seeks to investigate as a genre, not necessarily belonging to a marketing order, as the political discourse, is incorporating characters of promotional genres, most notably that of advertising. The approach is supported by the Critical Discourse Analysis, and other focal contributions. Became, therefore, a set of issues concerning the election guide 2010 presidential campaign.
\end{abstract}

\section{1) Introdução}

O presente trabalho busca investigar o fenômeno pelo qual um gênero discursivo passa a acomodar caracteres próprios de gêneros promocionais, mais especialmente os da publicidade. Para tal, examinará a reestruturação de um gênero vinculado à esfera do discurso político, o guia eleitoral (cf. LUNA, 2006), a partir da análise de como se dá a estruturação do design visual. $\mathrm{O}$ foco aqui será a metafunção representacional, correlata da função hallidayana ideacional e, mais propriamente, a relação das representações narrativas e seus processos - ação, reação, processo verbal, processo mental.

Fairclough (2001 [1992]) chama a atenção para o processo aqui em foco, ao explanar sobre a comodificação: domínios e instituições sociais, cujo propósito não seja o de produzir mercadorias no sentido econômico restrito de artigos para a venda, vêm, não obstante, a ser organizados e definidos em termos de produção, distribuição e consumo de mercadorias. Em termos de ordem de discurso, acentua o autor, podemos entender a comodificação como a colonização de ordens de discurso institucionais e mais largamente da ordem de discurso societária por tipos de discurso associados à produção de mercadoria.

O fenômeno passa a ser revisto a partir da consideração de dados aportes, ancorados no papel da linguagem na conjuntura das práticas sociais, especialmente no que se reporta ao processo atual na economia da sociedade moderna, o da globalização. Nesse contexto, Fairclough (2006) defende que a relação entre o 'fora' e o 'dentro' pode ser vista como uma relação de recontextualização - entidades externas são recontextualizadas, relocadas dentro de um novo contexto. Recontextualização pode ser, portanto, vista como uma relação dialética: ao mesmo tempo uma relação de colonização e de apropriação.

A amostra delimitada para esta abordagem foi resultante de pesquisa anterior sobre a recontextualização do guia eleitoral (PACHECO; COSTA, 2010; COSTA; PACHECO, 2010; COSTA; PACHECO, 2011). O material consta de dez edições do 
programa televisivo do guia eleitoral da candidata ao cargo político majoritário do país, Dilma Roussef, veiculadas em rede nacional de televisão entre o período de 17 de agosto a 30 de setembro de 2010. Destes, tomamos para recorte, análise e exposição no presente trabalho o primeiro programa exibido, por julgarmos ser significativo, principalmente em termos de trabalho de construção e consolidação de marca publicitária, fenômeno chave nesta investigação. A amostra foi tratada e analisada com base nos postulados teóricos erigidos para esta pesquisa, especialmente os enquadres da Gramática do Design Visual (KRESS; van LEEUWEN, 2006), da qual tomamos os elementos dos significados representacionais narrativos. Também consideramos elementos da teoria Telefílmica (IEDEMA, 2001; OUVERNEY, 2008), mais detidamente o nível do enquadramento, caracterizado pelo recorte saliente/representativo da fotografia.

\section{2) Da Análise Crítica do Discurso à linguagem publicitária: descortinando um aporte teórico}

A ACD considera o contexto de uso da linguagem como um elemento crucial, propondo pesquisas voltadas mais para relações sociais não tão estabilizadas de luta e conflito, materializadas por discursos como o institucional, o político, o de gênero (gender), o da mídia. Com isso, os conceitos de ideologia, poder e hierarquia vêm a ser fundamentais para a interpretação ou explicação do texto. A ACD leva em conta, ainda, os pressupostos de que: (a) o discurso é estruturado pela dominação; (b) cada discurso é historicamente produzido e interpretado, isto é, está situado no tempo e no espaço; (c) as estruturas de dominação são legitimadas pelas ideologias dos grupos que detêm o poder (cf. WODAK, 2004 [2001]).

Para a ACD, o discurso é tido como uma forma de prática social, realizada por intermédio de gêneros textuais. Isto tem as seguintes implicações (FAIRCLOUGH, 2001 [1992]): (a) os indivíduos realizam ações por meio da linguagem; (b) há uma relação bidirecional entre o discurso e as estruturas sociais, na exata medida em que o discurso é simultaneamente influenciado pelas estruturas sociais e as influencia; (c) há uma preocupação com os recursos empregados na produção, distribuição e consumo dos textos, recursos sociocomunicativos, porquanto perpassados por discursos e ideologias.

A partir da explanação de Fairclough (2001 [1992]), Meurer (2005, p. 82-83) expõe as seguintes perspectivas teóricas da ACD: a) o discurso é uma forma de prática social em relação dialética com estruturas sociais; b) o discurso tem poder constitutivo; c) os textos contêm traços e pistas de rotinas sociais complexas, mas os sentidos são muitas vezes naturalizados e não percebidos pelos indivíduos; d) os textos são perpassados por relações de poder; e) a ACD privilegia o estudo da interligação entre poder e ideologia; f) os textos formam correntes: respondem a, e podem provocar ou coibir, outros textos; g) a ACD cultiva uma perspectiva emancipatória.

Numa primeira fase dos estudos em ACD, Fairclough (1990; 2001 [1992]), ao conceber sua Teoria Social do Discurso, elaborou um modelo que considera três dimensões passíveis de serem analisadas: a do texto, a da prática discursiva e a da prática social. 
Figura 1: Modelo tridimensional do discurso

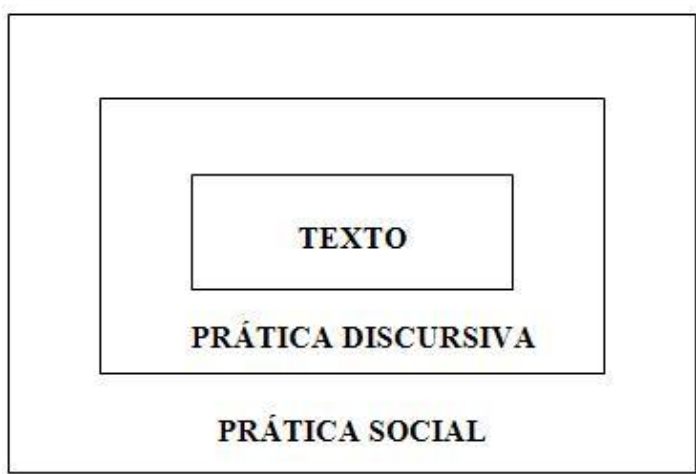

Fonte: Fairclough (2001 [1992], p. 101)

Diferentes categorias analíticas se enquadram em cada uma das dimensões. $\mathrm{Na}$ dimensão do texto devem ser observadas as categorias de vocabulário, gramática, coesão e estrutura textual, a fim de se observar a organização textual; na dimensão da prática discursiva devem ser examinadas as categorias de produção, distribuição e consumo de textos, bem como noções como contexto, força ilocucionária, coerência e intertextualidade, a fim de verificar o modo como o discurso é distribuído e consumido pela sociedade ou por grupos sociais específicos; na dimensão da prática social devem ser observadas as categorias de ideologia, sentidos, pressuposições, metáforas, hegemonia, orientações econômicas, políticas, culturais e ideológicas, a fim de se observar a manutenção ou a mudança que o discurso produziu na sociedade ou em grupos sociais particulares.

Mais recentemente, especialmente a partir dos estudos expostos em Chouliaraki e Fairclough (1999) e Fairclough (2003), a teoria caminhou para uma consideração mais enfática do papel crucial da prática social. Passou a ser posta em xeque a centralidade do discurso como foco dominante na análise, passando a ser visto como tão somente um dos momentos das práticas sociais. Foi nesse contexto que tomaram assento novos aportes, que se agregaram para reconstruir o arcabouço teórico da ACD: o Realismo Crítico, de Baskhar; a teoria crítica da racionalidade comunicativa, de Habermas; a teoria da estruturação, de Giddens; o materialismo histórico-geográfico, de Harvey; o tratamento da ideologia, de Thompson.

A abordagem, assim, passa a ser tomada como relacional, não apenas concernente a discurso e texto, mas na relação do discurso com outros elementos da vida social. Como aponta o próprio Fairclough (2006, p. 29): "a mudança social pode ser concebida como mudança nas relações entre os elementos sociais de todos os tipos, como uma 'rearticulação' de elementos sociais que os põe em novas relações”. Assim, o discurso é tomado como um elemento da prática social que tanto constitui outros elementos como é constituído por eles, em uma relação dialética de articulação e internalização: 
Figura 2: Momentos das práticas sociais

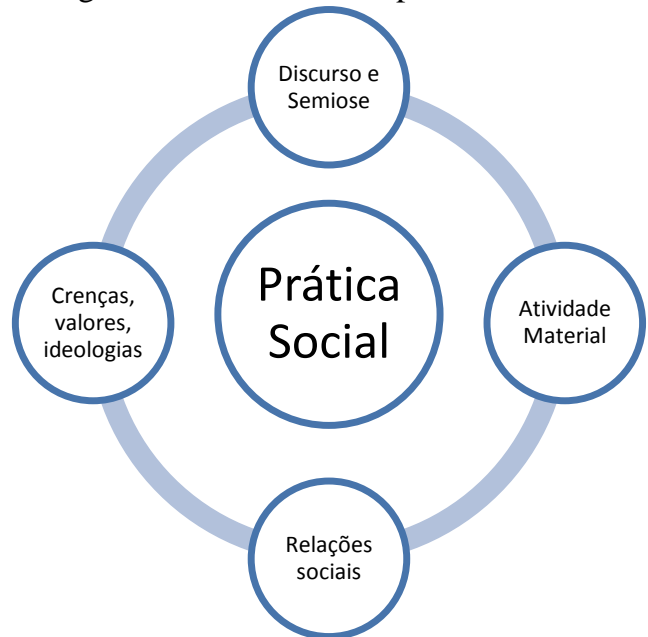

Fonte: Resende; Ramalho (2006, p. 39; 2011, p. 16); Resende (2009, p. 31)

O discurso é considerado, portanto, como um momento integrante e irredutível das práticas sociais que, como tal, envolve a linguagem em articulação com os demais momentos das práticas: a atividade material, as relações sociais, o fenômeno mental. É possível ainda enxergar o discurso, enquanto linguagem, como um momento crucial da vida social e, de um modo mais concreto, como um modo particular de representar parte do mundo.

Atualmente, percebemos um interesse especial pela relação entre a linguagem e o processo de globalização (FAIRCLOUGH, 2006), para o que se volta o olhar para as assim chamadas vozes da globalização, distintas em cinco principais agências: a análise acadêmica, as agências governamentais, as agências não-governamentais, a mídia, as pessoas na vida social. Nesse âmbito, um olhar mais acurado foi dado para o processo de recontextualização, já apresentado em Chouliaraki e Fairclough (1999), bem como retomado em Fairclough (2003), conceito muito caro para o nosso interesse no presente estudo.

Por outro lado, no que se reporta à linguagem publicitária, podem ser apontadas como cinco as tarefas básicas do fazer publicitário (VESTERGAARD; SCHRØDER, 1988, p. 47): "chamar a atenção; despertar o interesse; estimular o desejo; criar convicção; induzir a ação". Tais metas funcionam em coadunação com os elementos constitutivos do anúncio, segundo a concepção de Vestergaard e Schrøder (1988, p. 49): "título; texto; assinatura; slogan". Assim, funções como a da atenção e do interesse têm como elementos responsáveis o consórcio entre título, ilustração e slogan.

A par disso, a publicidade possui um componente icônico, uma imagem que é tipicamente uma cena que fornece um pano de fundo para o conjunto da peça publicitária. Usualmente, ela funciona como um componente interpretacional que guia $\mathrm{o}$ leitor para certos aspectos de sentido, possivelmente em uma relação bidirecional com o texto.

Imagem e texto estão dispostos articuladamente sob determinada organização que passa a ser um importante componente para o conjunto da peça publicitária. A 
organização pode sugerir coerência, algum modo de ordem em que as partes são interpretadas e a relevância que determina o modo particular de sentido que a publicidade possui.

A atividade consumidora, enfatiza Campos (1987), passa da consideração dos objetos em seu valor-de-uso (determinado pelas propriedades materialmente inerentes à mercadoria) à agregação de um valor-de-troca simbólico. Se o primeiro se pode definir em termos individuais, este último é estritamente social, por promover o relacionamento entre diversos produtores.

Assim, temos que a publicidade desloca o objeto de sua função de uso para uma função de signo, promovendo a acumulação e a proliferação dos objetos, numa política do supérfluo, numa extinção planejada daqueles por meio de sua reciclagem/perecibilidade, gerando necessidades e desejos que levam a um consumo recorrente e praticamente forçado.

Cabe ao publicitário, nesse sentido, para criar verdadeira convicção sobre a superioridade de um produto em relação aos concorrentes, o desenvolvimento daquilo a que Vestergaard e Schrøder (1988, p. 65) chamaram de Proposta Única de Venda (PUV): “o mais provável é que as PUV sejam essencialmente estéticas como o sabonete transparente ou a pasta de dentes com listas; a inovação estética em grande caso é revelada por uma inovação de estética linguística".

A par disso, o discurso publicitário, segundo Carvalho (1998, p. 59), "tem as características especificas da sociedade na qual se insere e é o testemunho autorizado dos imaginários sociais do contexto envolvente, revelando o funcionamento cultural", ajudando a configurar a publicidade como um grande instrumento da sociedade de consumo no sentido de tornar imóveis os códigos sociais existentes, colocando cada um dos indivíduos em seu devido lugar.

Bhatia (2004) faz uma abordagem detalhada sobre características formais e funcionais dos gêneros promocionais, dando destaque para o anúncio publicitário, do qual explana a estrutura dos movimentos retóricos. Nesse ponto, o autor ressalta que "um dos mais importantes movimentos no discurso da publicidade é 'oferecer uma descrição do produto' como bom, positivo e favorável” (BHATIA, 2004, p. 59). E aponta a publicitária como uma das mais dinâmicas e inovadoras formas de discurso hoje em dia, tendo influência na construção, interpretação, uso e exploração de muitas outras formas de gêneros acadêmicos, profissionais e institucionais.

Ao elaborar uma retrospectiva de suas pesquisas sobre a marca publicitária, Zozolli (2005) tece reflexões sobre a marca comercial/institucional, apreendida como bem simbólico, concebido como signo social resultante de um trabalho de coenunciação por parte dos agentes de sua produção e transmissão, do(s) destinatário(s), bem como do próprio mercado e da sociedade. E acrescenta remontando a uma constatação de que há muito tempo que empresas, instituições, associações, partidos e candidatos políticos, causas sociais, programas culturais, sociais, personalidades etc. vem a ser considerados produtos. É desse autor a afirmativa de que a marca é mercadoria. A marca comparece como mercadoria, uma vez que, no mercado de consumo sígnico, representa significações que vão ser produzidas, veiculadas e consumidas. 
O conjunto destes postulados põe, portanto, o próprio fazer publicitário como aquilo que nos confere o poder de dar um certo conteúdo representativo ao mundo dos produtos: como quis Péninou (1974), muitos não têm conteúdo para nós, não nos dizem nada e continuariam nada significando, a não ser pela promoção publicitária.

\section{3) Significados Representacionais, Processos narrativos e recontextualização do gênero guia eleitoral}

A natureza da abordagem teórico-metodológica da ACD conforme vimos aponta para uma orientação tanto linguística quanto social. Embora saibamos que esta dissociação entre faces linguística e social só seja possível didaticamente, para fins de exposição, poderíamos dizer que a face linguística da análise recebe uma forte influência dos pressupostos da Linguística Sistêmico-Funcional, caracterizada por estabelecer princípios gerais quanto ao uso da linguagem, investigando a relação entre as funções e o sistema interno da língua. A relação entre as funções sociais da linguagem e a organização do sistema linguístico é tomada como um traço constitutivo da linguagem humana. Tomar o sistema interno da língua sob o foco das funções sociais se apresenta como sumamente necessário.

Nesta perspectiva, temos que o significado linguístico, em sua interface com o aparato lexicogramatical, não se apresenta em uma relação especular com a realidade. $O$ que temos são dimensões da estrutura semântica que se organizam para a construção em três dimensões: como representação, como intercâmbio, como texto (HALLIDAY; MATHIESSEN, 2004, p. 20; GHIO; FERNÁNDEZ, 2008, p. 91) . Assim, temos um princípio metafuncional ideacional, quando da utilização da linguagem para organizar, compreender e expressar as nossas percepções do mundo e a nossa própria consciência, para descrever eventos, estados e as entidades nele envolvidas; uma metafunção interpessoal, porquanto utilizamos a linguagem para participarmos de atos de comunicação com outras pessoas, para com elas interagirmos, para com elas estabelecermos e mantermos relações sociais, para influenciarmos seus comportamentos ou para lhes expressarmos os nossos pontos de vista sobre a realidade; uma metafunção textual, quando utilizamos a linguagem para organizar e relacionar o que dizemos ou escrevemos com outros eventos linguísticos e com o mundo real.

Para o objeto do presente trabalho, nos deteremos na análise de um fenômeno com o foco mais na metafunção ideacional através da transitividade, categoria "responsável pela materialização desse conjunto de atividades [fluxo de eventos ou acontecimentos, atos, ligados a agir, dizer, sentir, ser e ter] através dos tipos de processos (verbos), com cada tipo modelando uma fatia da realidade" (CUNHA; SOUZA, 2007, p. 53). 
Quadro 1: Processos, significados e participantes do sistema de transitividade

\begin{tabular}{|c|c|c|c|}
\hline Processo & Significado & $\begin{array}{l}\text { Participantes } \\
\text { obrigatórios }\end{array}$ & $\begin{array}{l}\text { Participantes } \\
\text { opcionais }\end{array}$ \\
\hline Material & Fazer, acontecer & Ator & $\begin{array}{l}\text { Meta, Extensão e } \\
\text { Beneficiário }\end{array}$ \\
\hline Mental & Sentir & $\begin{array}{l}\text { Experienciador } \\
\text { Fenômeno }\end{array}$ & \\
\hline Relacional & Ser & & \\
\hline Atributivo & Classificar & Portador e Atributo & \\
\hline Identificador & Definir & Característica e Valor & \\
\hline Verbal & Dizer & Dizente e Verbiagem & Receptor \\
\hline Existencial & Existir & Existente & \\
\hline Comportamental & Comportar-se & Comportante & Behavior \\
\hline
\end{tabular}

Fonte: Cunha e Souza (2007, p. 60).

Ainda sob os propósitos levantados desde a introdução deste trabalho, vamos tomar os postulados da gramática do design visual, a qual faz uso de uma organização metafuncional, construindo seus significados a partir das funções tais como concebidas pela Linguística Sistêmico-Funcional, de Halliday:

Quadro 2: Correlação LSF/GDV

\begin{tabular}{|l|l|l|}
\hline Halliday & $\begin{array}{l}\text { Krees; } \\
\text { van Leeuwen }\end{array}$ & \multicolumn{1}{|l}{} \\
\hline Ideacional & Representacional & $\begin{array}{l}\text { Responsável pelas estruturas que compõem visualmente a } \\
\text { natureza dos eventos, objetos e participantes envolvidos, } \\
\text { e as circunstâncias em que ocorrem. Indica em outras } \\
\text { palavras o que nos está sendo mostrado, o que se supõe } \\
\text { esteja "ali", o que está acontecendo, ou quais relações } \\
\text { estão sendo construídas entre os elementos apresentados. }\end{array}$ \\
\hline Interpessoal & Interativa & $\begin{array}{l}\text { Responsável pela relação entre os participantes, é } \\
\text { analisada dentro da função denominada de função } \\
\text { interativa (KREES; VAN LEEUWEN, 2006), onde os } \\
\text { recursos visuais constroem "a natureza das relações de } \\
\text { quem vê e o que é visto". }\end{array}$ \\
\hline Textual & Composicional & $\begin{array}{l}\text { Responsável pela estrutura e o formato do texto, é } \\
\text { realizada na função composicional na proposição para a } \\
\text { análise de imagens de Krees; van Leeuwen, e se refere } \\
\text { aos significados obtidos por meio da "distribuição do } \\
\text { valor da informação ou ênfase relativa entre os elementos } \\
\text { da imagem". }\end{array}$ \\
\hline
\end{tabular}

Fonte: Almeida (2008, p. 12).

O sistema de transitividade, tal como conceito da proposta da Linguística Sistêmico-Funcional, encontra seu correlato na Gramática do Design Visual nos elementos da função representacional, obtida nas imagens através dos participantes representados, que podem ser pessoas, objetos ou lugares. Kress e van Leeuwen (2006) subdividem essa função em estrutura narrativa, quando há presença de vetores indicando que ações estão sendo realizadas, ou conceitual, quando existe uma taxonomia. 
Figura3: Resumo dos significados representacionais

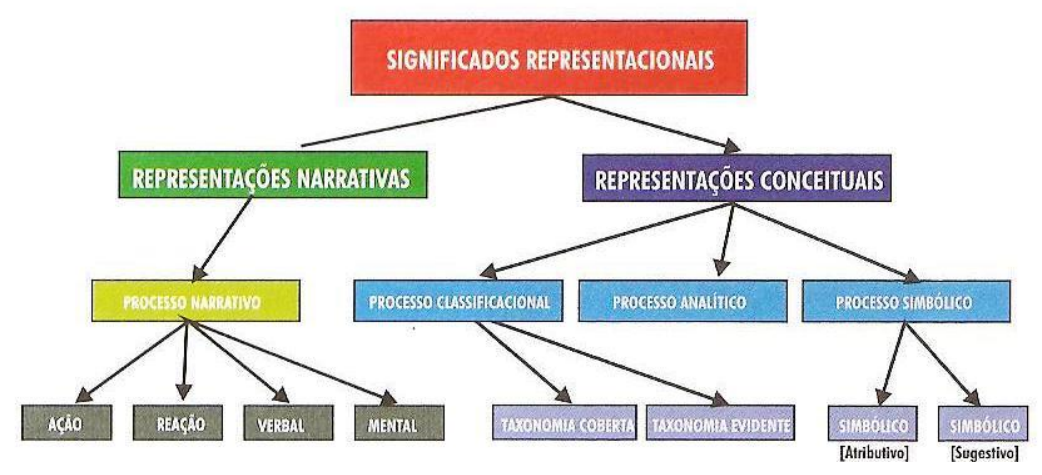

Fonte: Cardoso (2008, p. 67)

No que se refere às representações narrativas, temos que os participantes se engajam em eventos e ações, podendo estabelecer uma relação entre si. O que distingue uma proposição visual narrativa é a presença de uma ação, desempenhada por um vetor. De acordo com o tipo de vetor e número de participantes envolvidos, é possível perceber alguns processos narrativos: ação (ator, meta, interatores), reação (reator, fenômeno), processo verbal (dizente, enunciado), processo mental (experienciador).

$\mathrm{Na}$ amostra em análise podemos destacar o uso de elementos da proposição visual narrativa. Logo na primeira cena da edição, vemos a imagem de um carro que avança em direção a Brasília, detalhe que podemos depreender pela característica edificação da ponte JK, que vai se descortinando. No carro, paralelamente à elocução de sua voz, vemos a silhueta da candidata Dilma Roussef, que vislumbra o cartão-postal, à medida que avança e tergiversa sobre assuntos paralelos aos de sua plataforma de campanha. Aqui, numa estrutura considerada transacional, temos dois participantes: um ator, marcado pela figura humana da silhueta de Dilma, aquele do qual parte um vetor, responsável pela direção de movimento; um outro se identifica como a meta, definida pela edificação, simbolizando Brasília, o epicentro do poder, se tomarmos o contexto de situação, marcado por uma disputa acirrada entre candidatos ao cargo eletivo majoritário.

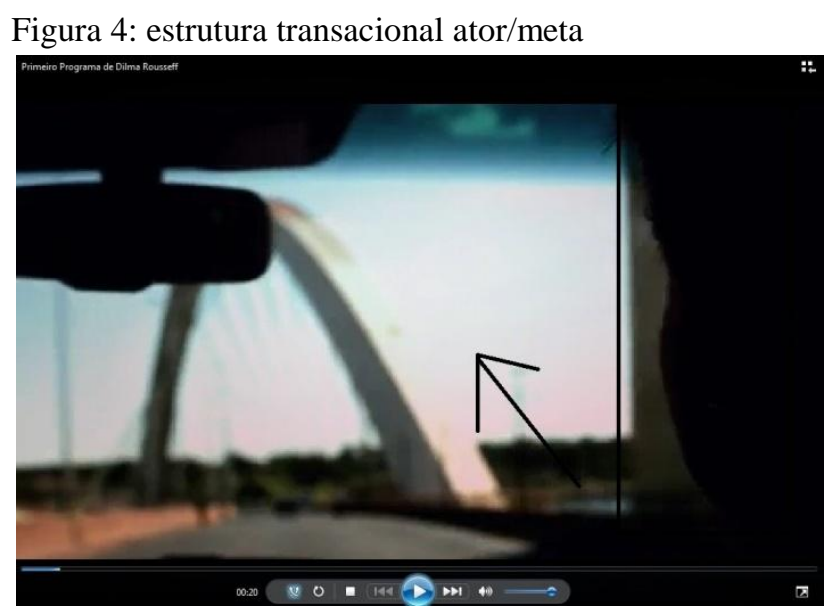

Fonte: Campanha Dilma Presidente 2010. 
O recurso telefílmico utilizado aqui é o da oculização (câmera por detrás), em que o espectador tem um foco de privilégio, comungando do olhar e da ação do protagonista da cena. Para um caso como este, Sells e González (2003) veriam a presença de um terceiro participante do enquadre visual, o espectador, (e)leitor, que acompanha o ator na realização em direção à sua meta. Talvez não seja desarrazoado propor este tipo de organização visual, quando se trata do estabelecimento de uma campanha eleitoral e se passa a 'convidar' o potencial eleitor, em um exercício de indução, convicção, persuasão. O recurso vai se repetir em outras cenas como é o caso do enquadre seguinte:

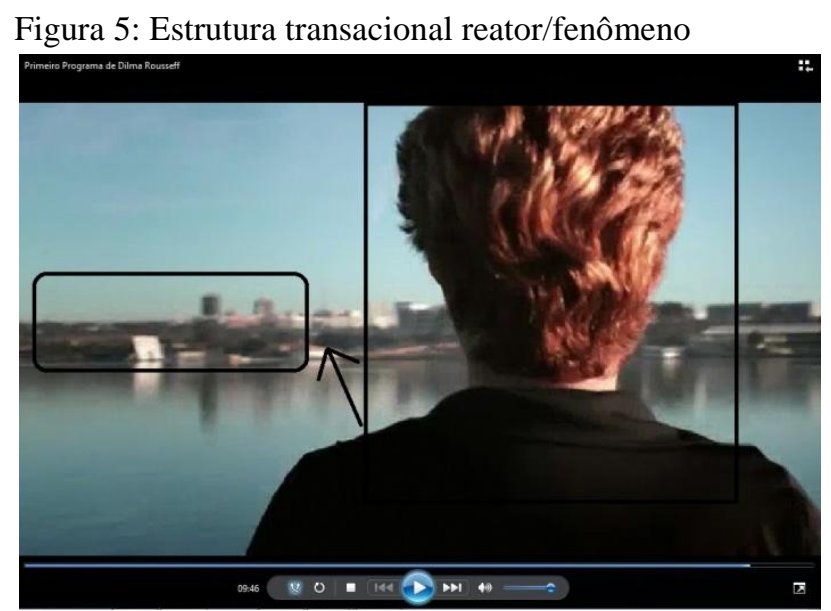

Fonte: Campanha Dilma Presidente 2010

Na cena da figura 5, temos uma ação marcada pelo olhar, sendo o participante principal, marcado pela figura de Dilma, considerado o reator, separado por uma faixa tênue, mas considerável, a imagem de outro ponto topográfico chave, o lago Paranoá. De seu outro lado, a imagem pouco distante, mas nítida de Brasília. O recurso fílmico mais uma vez leva o (e)leitor a compartilhar do objeto para o qual se direciona o vetor, aqui, por se tratar de ação visual marcada pelo olhar, chamado de fenômeno.

Cardoso (2008), como podemos observar na figura 6, vai buscar resultados congruentes aos nossos ao analisar o papel dos componentes visuais do anúncio publicitário na construção do recurso persuasivo, especificamente para o caso que nos interessa de perto, o das representações narrativas, potencializadas pelos elementos ator/vetor/meta, quando da associação com o apelo em favor da obtenção de um produto e seus adjuvantes: aquisição, compra, consumo.

Figura 6: Significado representacional da imagem em anúncio publicitário 


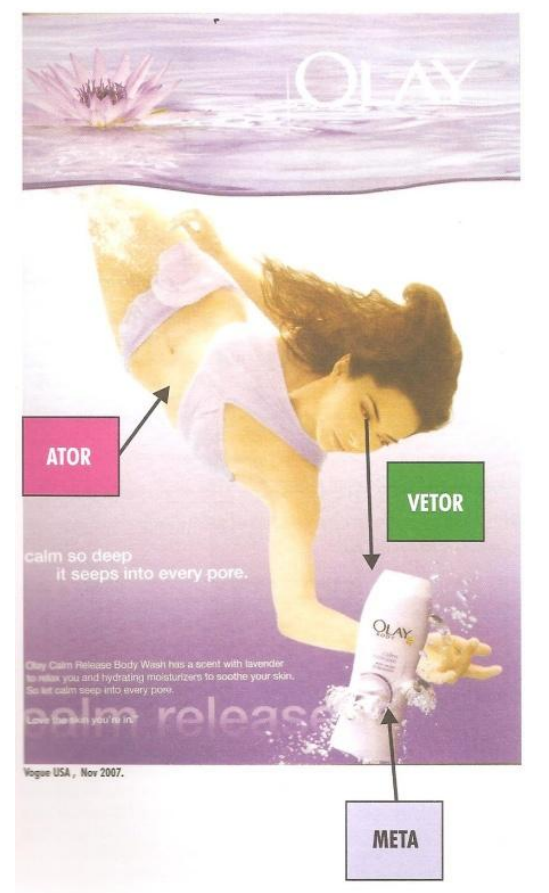

Fonte: Cardoso (2008)

Em nosso caso, pelo recurso telefílmico da oculização, cumulam a meta do participante ator na imagem (a figura humana da então candidata Dilma) com a do participante espectador/(e)leitor/consumidor, que acabam assumindo, pelo direcionamento da linha vetorial, o objeto de desejo, o poder. Este, no enquadre, vem representado pelas edificações emblemáticas da cidade de Brasília. Diante de um apelo publicitário que reza "compre $x$ e obtenha o sucesso, o conforto, a realização", temos uma máxima que sugere algo como "compre o 'produto' Dilma/Presidente e obtenha o objeto de desejo, o poder (que "emana do povo" (?)). Por consequência, temos os procedimentos que trabalham em função da construção e consolidação da marca Dilma/Presidente e o que esta (a marca) proporciona: identificação, localização, garantia, personalização, praticidade, confiança, além da consolidação de um mecanismo de PUV, a tal Proposta Única de Venda.

Aliás, a construção da marca pode ainda ser depreendida a partir de outros recursos, organizados em termos da estruturação do design visual do desenvolvimento cena/sequência da edição do guia eleitoral em foco. Na figura 7, abaixo, temos a estrutura bidirecional, com interatores, marcada pela ação do cumprimento e a troca incisiva dos olhares. Essa configuração, que aponta para uma característica colaborativa na ação, vai se repetir no filme, em uma cena emblemática, como podemos depreender pela figura 8 . 
Figura 7: Estrutura transacional/bidirecionalidade

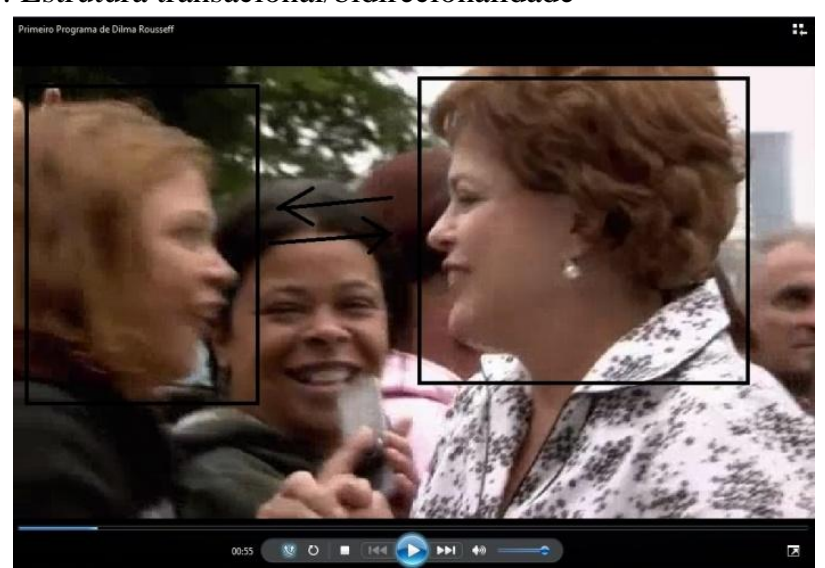

Fonte: Campanha Dilma Presidente 2010.

Neste último caso (figura 7), além de enfatizar, como no caso da figura 8, o caráter colaborativo, a narrativa levanta um dos recursos mais relevantes da argumentação publicitária: o apelo à autoridade. Este ocorre quando, para o estabelecimento ou consolidação de uma marca, é chamada uma figura de destacado e reconhecimento prestígio para 'emprestar' seu aval em favor do procedimento de qualificação do produto. A cena aqui em questão (com fotografia em preto e branco para marcar o recurso do flash-back), traz para o enquadre a figura do então presidente Luiz Inácio Lula da Silva, gozador de ampla popularidade à época e politicamente interessado na eleição de sua sucessora.

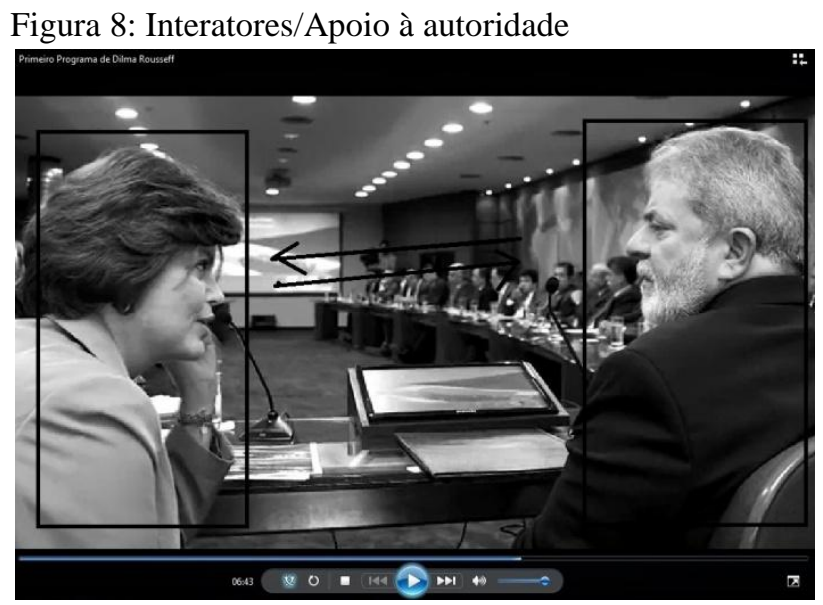

Fonte: Campanha Dilma Presidente 2010

Embora ainda de modo limitado, até pela natureza mesma do presente trabalho, o conjunto dos dados expostos aponta para um fenômeno de grande impacto na constituição das práticas sociais e discursivas na atualidade, qual seja, o da recontextualização de ordens de discurso. Para o caso aqui específico, nota-se uma relevante reestruturação de um gênero, o guia eleitoral, não diretamente, em princípio, ligado à atividade social de produção de mercadorias para consumo. Para esse caso, tal reordenação vem se estabelecendo em função do movimento colonizador da 
publicidade, esta sim imbuída das práticas de produção, distribuição e consumo de mercadorias.

\section{5) Balanço e considerações finais}

Os resultados até aqui cotejados apontam para um premente processo de recontextualização da ordem de discurso político pela reestruturação do gênero não promocional guia eleitoral televisivo. Tal constatação vai ao encontro das nossas investigações anteriores sobre o tema (PACHECO; COSTA, 2010; COSTA; PACHECO, 2010; COSTA; PACHECO, 2011), em que o foco foi a metafunção composicional, visando a um exame da distribuição do valor da informação e ênfase dos elementos do design visual. E, perpendicularmente, quando nos reportamos ao movimento, na esteira de Bhatia $(2001 ; 2004 ; 2008)$, no que tange à análise de gêneros textuais, especificamente àquilo relativo a como gêneros pertencentes a uma ordem não necessariamente mercadológica, passam a incorporar características estruturais e discursivas de gêneros promocionais, mais especialmente as do anúncio publicitário (COSTA; BEZERRA, 2013).

O processo de recontextualização, vale dizer, se dá de um modo dialético: não é tão somente a um movimento colonizador do discurso mercadológico da publicidade; é igualmente flagrante uma reestruturação das ordens não necessariamente econômicas como a do discurso político, em um procedimento de apropriação dos recursos semióticos das práticas discursivas promocionais.

Nesse sentido, é provável constatar que a prática societária do discurso político, acaba, como constatou Charaudeau (2008), por oscilar entre um ideal de credibilidade e captação. Ela é o resultado da construção de uma identidade discursiva pelo sujeito, realizada de tal modo que os outros sejam conduzidos a julgá-lo digno de crédito. Já no discurso publicitário não há necessidade de se mostrar crível, posto que, para esse caso, seria tão somente necessário desencadear no potencial consumidor um desejo de crer: "não é preciso que a promessa se realize, basta que ela faça sonhar" (CHARAUDEAU, 2008 , p. 119). Entretanto, a prática política trabalha com a função de angariar votos e, no entremeio, captar a anuência de um número maior possível de potenciais eleitores. Começa a se configurar, a partir desse ponto fulcral, a necessidade de construção de um fazer publicitário, ancorado nas atividades de chamar a atenção, despertar o interesse, estimular o desejo, criar convicção, induzir a ação última do sufrágio do voto.

\section{Referências}

ALMEIDA, Danielle. Perspectivas em análise visual. João Pessoa: Editora da UFPB, 2008.

BHATIA, Vijay. Towards critical genre analysis. In: BHATIA, V.; FLOWERDEW, J.; JONES, R. (Ed.) Advances in discourse analysis. London/New York: Routledge, 2008.

Worlds of written discourse: a genre-based view. London: Continuum, 2004. 
[1997] Análise de gêneros hoje. Revista de Letras, v.1, n. 2, jan./dez 2001.

CAMPANHA Dilma Presidente 2010. Disponível em: 〈http://www.dilma13.com.br>. Acesso em 10 out. 2010.

CAMPOS, Maria Helena. O canto da sereia: uma análise do discurso publicitário. Belo Horizonte, Ed. UFMG/PROED, 1987.

CARDOSO, Jacilene. A imagem como recurso persuasivo na propaganda. In: ALMEIDA, Danielle. Perspectivas em análise visual. João Pessoa: Editora da UFPB, 2008.

CARVAlHO, Nelly. O batistério publicitário. Alfa - Revista de Linguística. São Paulo, v. 42. n. esp., 1998, p. 57-70.

Publicidade: a linguagem da sedução. São Paulo: Ática, 1996.

CHARAUDEAU, Patrick. Discurso político. São Paulo: Contexto, 2008.

CHOULIARAKI, L.; FAIRCLOUGH, N. Discourse in late modernity: rethinking Critical Discourse Analysis. Edinburgh: Edinburgh University Press, 1999.

COSTA, Ivandilson; BEZERRA, Benedito. Análise crítica de gêneros textuais: o guia eleitoral recontextualizado. Intersecções: revista de estudos sobre práticas discursivas e textuais. Jundiaí, v. 6, n. 2, nov. 2013.

COSTA, Ivandilson; PACHECO, W. A política recontextualizada: questões de colonização publicitária no discurso político. Domínios de Linguagem. Uberlândia, v. 5, n. 1, jan./jun 2011.

COSTA, Ivandilson; PACHECO, W. A publicidade onipresente: o discurso político colonizado. Revista Voos. Guarapuava, v. 2, n. 1, jul. 2010.

CUNHA, M. Angélica; SOUZA, M. Medianeira. Transitividade e seus contextos de uso. Rio de Janeiro: Lucerna, 2007.

FAIRCLOUGH. Norman. Language and Globalization. London; New York:

Routledge, 2006.

Analysing discourse: textual analysis for social research. London/New York:

Routledge, 2003.

Discurso e mudança social. Brasília: Editora da UnB, 2001.

Language and power. 2. ed. London: Longman, 1990.

GHIO, E.; FERNÁNDEZ, M. Lingüística sistémico funcional: aplicaciones a la lengua española. Santa Fe: UNL, 2008.

HALLIDAY, M. ; MATHIESSEN, C. Introduction to functonal Grammar. London: Arnold, 2004. 
KRESS, G.; LEEUWEN, T. van. Reading images: the grammar of visual design. 2. ed. London/New York: Routledge, 2006.

IEDEMA, Rick. Analysing film and television: a Social Semiotic account of hospital an unhealthy business. In: LEEUWEN, T. van; JEWITT, C. Handbook of visual analysis. London: Sage, 2001.

LUNA, Tatiana. Guia eleitoral: as relações dialógicas e a construção do posicionamento discursivo na campanha eleitoral majoritária do Recife em 2004. Dissertação (Mestrado em Letras). 2006. 136 f. Universidade Federal de Pernambuco. Recife: 2006.

MEURER, J. L. Gêneros textuais na análise crítica de Fairclough. In: MEURER, J. L.; BONINI, A.; MOTTA-ROTH, D. (Org.) Gêneros: teorias, métodos, debates. São Paulo: Parábola, 2005. p. 81-106.

OUVERNEY, Jamylle. A mulher retratada em comerciais de cerveja: venda de mulheres ou de bebidas? In: ALMEIDA, Danielle. Perspectivas em análise visual. João Pessoa: Editora da UFPB, 2008.

PACHECO, W; COSTA, I. A política publicizada: análise da colonização de ordem de discurso. In: Salão de Iniciação Científica da Universidade do Estado do Rio Grande do Norte, 6, 2010, Mossoró. Anais (on-line). Mossoró: UERN, 2010. Disponível em: <http://www.uern.br/sic/sic2010/arquivos/VI SIC.pdf>. Acesso em 18 jun. 2013.

PÉNINOU, Georges. O sim, o nome e o caráter. In: et al. Os mitos da publicidade: seleção de ensaios da revista "Communications". Petrópolis: Vozes, 1974.

RESENDE, Viviane. Análise de discurso crítica e realismo crítico: implicações interdisciplinares. São Paulo: Pontes, 2009.

RESENDE, V.; RAMALHO, V. Análise de discurso (para a) crítica: o texto como material de pesquisa. São Paulo: Pontes, 2011.

Análise de Discurso Crítica. São Paulo: Contexto, 2006.

VESTERGAARD, T.; SCHRØDER, K. A linguagem da propaganda. Martins Fontes: São Paulo, 1988.

WODAK, Ruth. Do que trata a ACD: um resumo de sua história, conceitos importantes e seus desenvolvimentos. Linguagem em (Dis)curso, Tubarão, v. 4, n. esp., p. 233-243, 2004 [2001].

ZOZZOLI, Jean-Charles. A marca comercial-institucional: retrospectiva e prospecção. In: BARBOSA, I. S. (Org.) Os sentidos da publicidade: estudos interdisciplinares. São Paulo: Thomson, 2005. 